\title{
SIMULATION OF BIO-MECHATRONIC ELECTRICAL SUBSTATION USING RENEWABLE ENERGY
}

\author{
Alexey Grigoryevich Bulgakov* \\ Southwest State University, Kursk, Russia \\ Daher Sayfeddine \\ South Russian State Polytechnic University, Novocherkassk, Russia
}

More attention is being offered to renewable energy due to its cost effectiveness, ecological compatibility and optimized service transportation. In fact, many governments are dictating green energy standards to newly constructed buildings and compounds. Realizing its importance and ability to replace traditional energy sources, the green energy resources requires infrastructures and setups thus to generate consistent and reliable power. In view of that, the paper studies a bio-mechatronic control and monitoring system for an electrical substation using the internal wave energy. The electrical substation is part of self-sufficient standalone agro-industrial compound. The paper is structured around adequate mathematical model of the bio-mechatronic electrical substation and supported by simulation results of generating consistent electrical power and Steady-state stator current.

Key words: Renewable energy, Bio-mechatronic system, Green energy

\section{INTRODUCTION}

Since the very beginning of his existence, human being has realized the importance of power for his survival. Having consistent fire source remained one of the crucial tasks, since it was used for food preparation, hunting, heating and protection from several surrounding dangers. Along with the technological progress, the "red flower" produced with sparkles and timber was replaced with other energetic resources, which were more reliable for social and economical development.
After the end of the Second World War, nuclear power systems and researches for its applications in medical, military and power fields have multiplied several times. In 1986, Chernobyl nuclear disaster occurred, raising questions marks on the reliability and safety of nuclear energy management and control systems. Many other radioactive incidents were registered before and after 1986 as well. The official count illustrates 101 radioactive incidents (Figure 1 ).

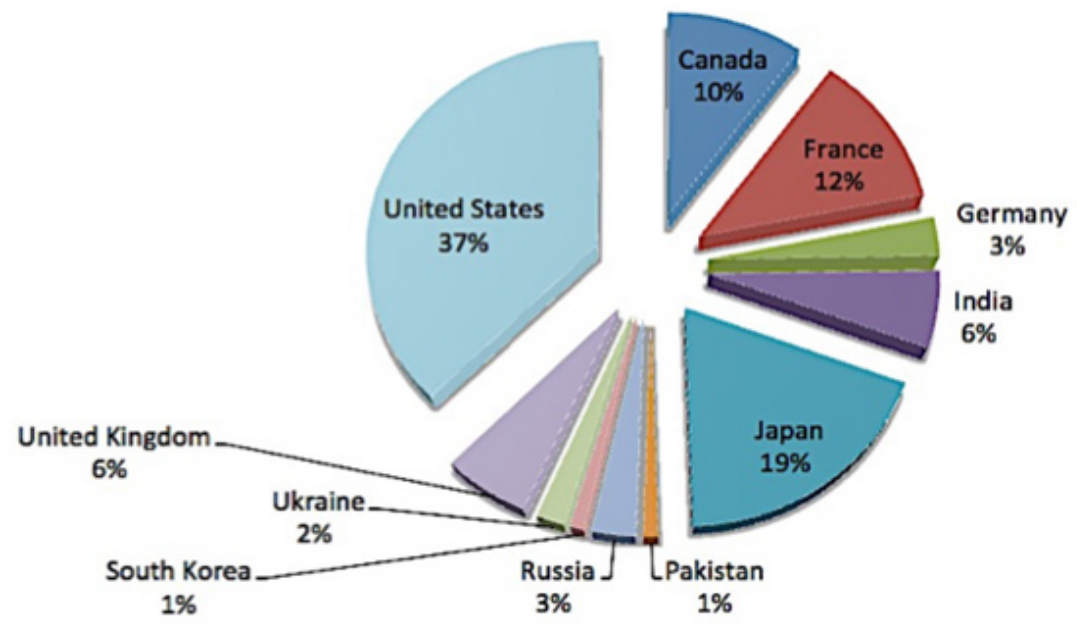

Figure 1: Radioactive incidents per country 
Green energy has been very topical recently. It is safe and self-sufficient. Along with political factors, the only economic reason disturbing the spreading of these solutions is the need to invest properly in infrastructure. Nevertheless, governments around the world are developing self-sufficient compounds, where energy is being produced, used and even distributed to other habitats, factories and cities. Worldwide, over 3560.4 TW.h/year (Terra Watt hours/year) of electricity production from renewable sources is produced (Figure 2.). While the hydropower sources produce the most electricity $(75.3 \%)$, wind-power $(14.12 \%)$, biomass $(6.93 \%)$, solar $(2.97 \%)$ and geothermal sources $(0.55 \%)$ contribute by $24.7 \%$ of the worldwide electricity production.

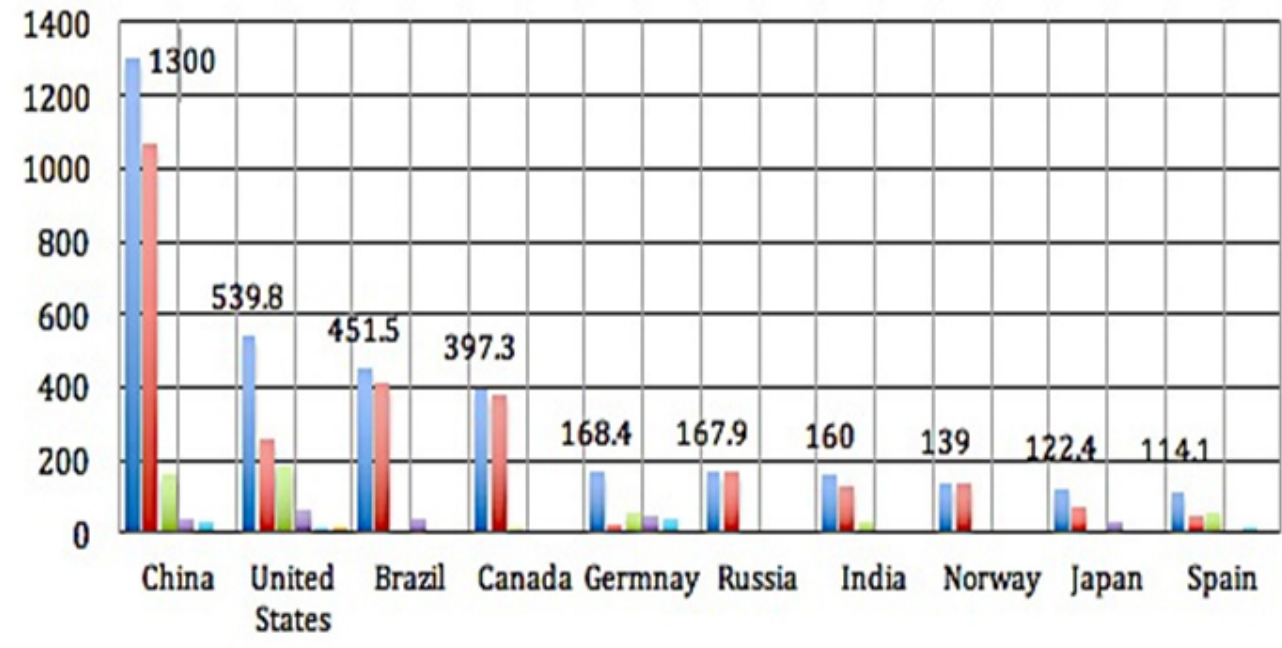

- Terra-Watthours / year " Hydropower "Windpower $=$ Biomass $=$ Solar $\equiv$ Geothermal

Figure 2: Production of energy from renewable sources by country

This paper presents a simulation for bio-mecha- compound. The concept design is depicted in tronic stand-alone self-sufficient electric substation using renewable energy for agro-industrial

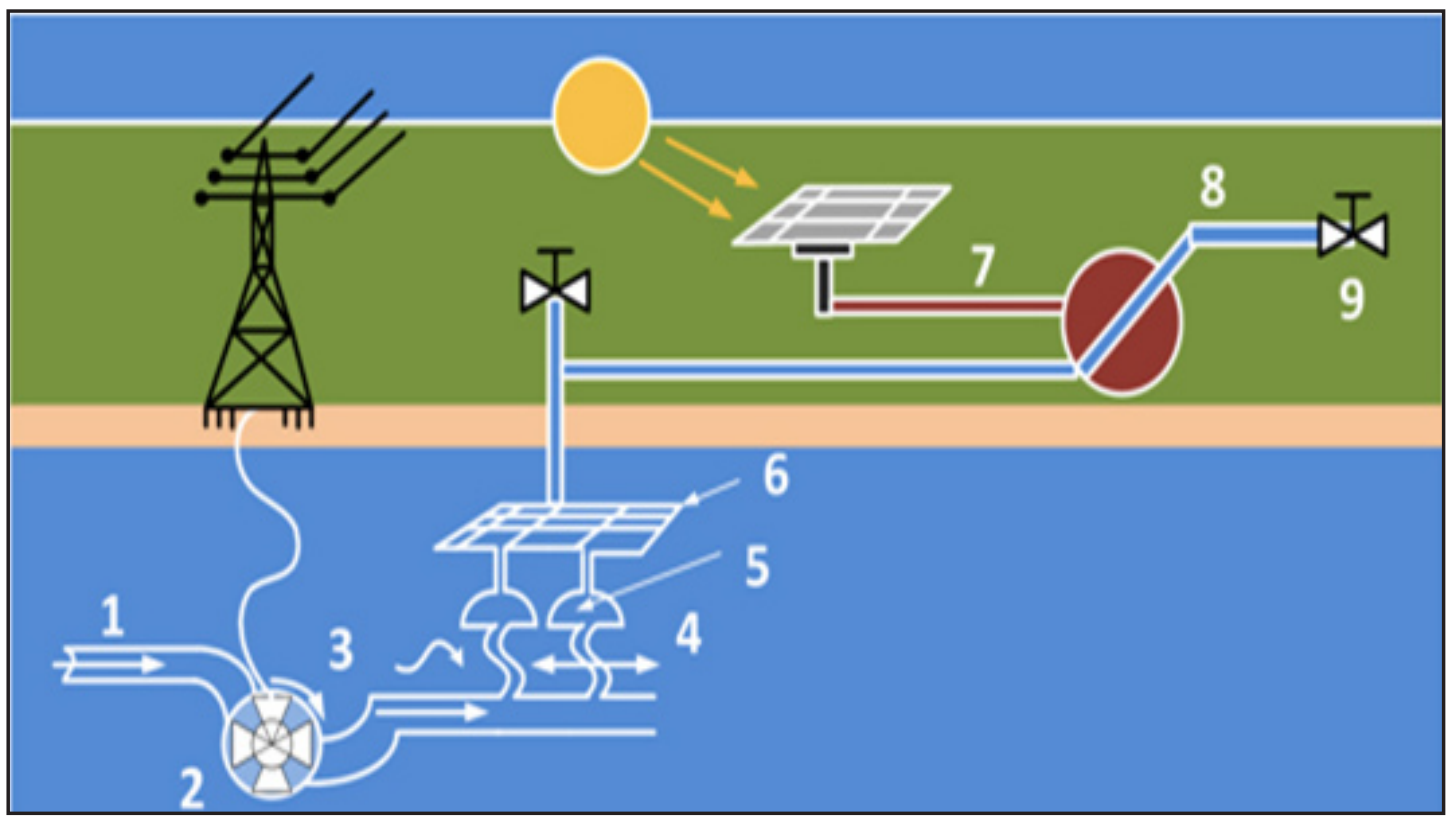

Figure 3: Conceptual design of the bio-mechatronic system 


\section{DESCRIPTION OF THE CONCEPTUAL DESIGN}

The bio-mechatronic water filtration and energy systems are divided into three major pillars: hydropower, mechanical and solar subsystems. They include the following components and natural sources (Figure 3): 1- are the sea waves; 2 - is the turbine; 3-are the pipeline; 4 - is jet mechanical filtration system; 5 - is jellyfish pneumatic mechanism; 6- are salt filters; 7 -is solar energy; 8- are the water boilers and 9- is the water condensation

The output of the subsystems is a releasable marketable product, having two characteristics:

a. The product value is incremental;

b. The product development is iterative, which means the process should be repeated thus to achieve consistency and quality.

Under product the following outputs are categorized:

- Electricity from hydropower plant;

- Hard water from the mechanical filtration mechanisms;

- Low-quality salt from the jellyfish mechanism;

- High-quality salt from the boiler system;

- Soft water from the condensation system.

\section{Hydropower plant simulation}

The hydropower plant consists of pipelines and turbine systems installed under the water. The efficiency of this plant depends of the sea or oceans internal waves oscillating where low density water overlies high-density water. Usually, the internal waves propagate along the boundary. They are especially common over the continental shelf regions of the world oceans and large rivers. Hence, the geographical positioning of the hydropower plant should be on a costal area.

Taking into consideration that the internal waves serve as input the described bio-mechatronic system and the water slab is uniform, the mathematical description of the cause production the internal wave is given is the following equation:

$\mathrm{J}=\frac{\mathrm{r}_{1}-\mathrm{r}_{2}}{2} \cdot g$

Where, $\mathrm{J}$ is the reduced gravity based on the density difference; $r_{1}$ first volume density of the double-layer uniform water slab; $r_{2}$ second vol- ume density of the double-layer uniform water slab and $g$ is the Earth's gravity.

Due to the variation of the reduced gravity over the day, the released product (electricity) fluctuates, which endangers the consistency of the compound production and maximize its dependency for external energy supplies. In order to maintain stable electricity production from the hydropower plant, the hydro turbine speed should be regulated. In order to achieve that, the frequency and active power should be regulated in accordance with the deviation of the water load. Hence, the control diagram of the turbine can be illustrated in the following Figure (4):

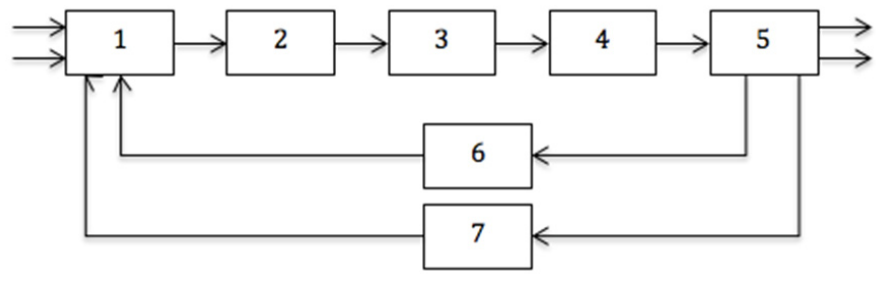

Figure 4: Hydropower plant control block-diagram 1-controller; 2-control mechanism; 3- gate; 4- turbine penstock; 5- generator; 6- power transducer; 7- frequency transducer

The block diagram can be described as follows: The inputs of the controller 1 are power and frequency variables. The stored volume water at certain depth contains potential energy. This energy is converted to kinetic energy. When it is allowed to pass through the penstock 4 through the gate 3 controlled by a servomotor 2 , this kinetic energy is converted to mechanical energy, which allows water to fall on the runner blades of the turbine. As the shaft of the generator 4 is coupled to the turbine, the generator produces electrical energy by converting the mechanical energy into electrical energy. The speed governing system of turbine adjusts the generator speed based on the feedback signals 6 and 7 of the deviations of both system frequency and power with respect to their reference settings. This ensures power generation at synchronous frequency.

\section{Mathematical model of servomotor}

The functions of the torque $M$ and flow $Q$ of the turbine are described in the following equations respectively:

$$
\begin{aligned}
& Q(x, y, H)=e_{q x} x+e_{q y} y+e_{q h} h ; \\
& M(x, y, H)=e_{x} x+e_{y} y+e_{h} h
\end{aligned}
$$


Where, $x$ is the turbine speed; $y$ is the gate opening and $h$ is the water head; $e_{q x}, e_{q y}$ and $e_{q h}$ are the partial derivatives of flow to speed of the turbine, flow to gate opening and flow to the head of the turbine respectively; $e_{x}, e_{y}$ and $e_{h}$ are partial derivatives of torque to the speed of the turbine, the torque to gate opening and the torque to the head of the turbine respectively.

The torque of the servomotor regulating the opening of the gate is described using Taylor series. Taking into account the zero initial conditions and neglecting of higher order terms in the series, the torque equation of the servomotor is simplified. We will limit the development of the mathematical model of the servomotor as it can be found in the literature [05]. The Laplace transfer function of the servomotor is given bellow:

$$
W_{S M}(p)=Q(p) / E(p)=K_{a} / p\left(t_{a p}+1\right)
$$

Where, $W_{S M}(p)$ is the transfer function of the servomotor; $Q(p)$ Laplace form of the rotational speed of the servomotor; $E(p)$ Laplace form of the deviation in rotational speed; gain $K_{a}=1 / B+f$ ; and time $t_{a}=J / B+f$ are functions of $B, J$, and $f$ - being the friction coefficient, moment of inertia and negative partial derivative of the servomotor torque against the acceleration $\mathrm{f}=\mathrm{dTsM} / \mathrm{dQ}$ respectively.

\section{Mathematical model of the hydro turbine}

This section represents an ideal hydro turbine taking into consideration the smoothness of the turbine blades, no water hammer effect on the penstock, the water is uniform and has no compression factor, where the water flow varies simultaneously with the opening angle of the gate. Building on that, the generated power in turbine can be given as:

$\mathrm{P}_{\mathrm{T}}=\mathrm{A}_{\mathrm{T}} \mathrm{H}\left(\mathrm{Q}-\mathrm{Q}_{\mathrm{n}}\right)$;

Where $P_{T}$ is the generated power; the turbine gain $A_{T}=1 / L_{F L}-L_{N L}$ and $L_{F L}$, $L_{N L}$ being the full-load and no-load gate opening and $Q_{n l}$ is the no-load flow rate.

The velocity of the water in the penstock $U$ is given by:

$U=K_{U} G \sqrt{H}$

Where $\mathrm{K}_{U}$ is a proportional coefficient; $\mathrm{G}$ is the gate opening in rad and $\mathrm{H}$ is the water head.

The acceleration of the water flow in the penstock is described in the following equation: $\frac{d U}{d t}=-a_{q} L\left(H-H_{0}\right)$

Where $a_{p}$ is the acceleration caused by gravity and $L$ is the length of the penstock.

By linearization of equations (6) and (7) and using equation (5), the lost generated power $\mathrm{P}_{\mathrm{L}}$ equation can be described as:

$\mathrm{P}_{\mathrm{L}}=\mathrm{U}_{\mathrm{NL}} \mathrm{H}$

Where $U_{N L}$ - is the no-load speed.

Using linearized equations (6) and (7), we can find the transfer function relating the flow to the net water head, which is described in the following equation:

$$
\frac{\bar{U}}{\overline{H-H_{0}}}=-\frac{1}{T_{w} p}=-\frac{1}{\frac{L Q_{r}}{a_{g} A H_{r}} p} ;
$$

Where $\mathrm{H}_{0}$ is the static water head and $\mathrm{T}_{w}$ is the water starting time at rated load having a rated flow $Q_{r}$ and rated water head $H_{r}$.

\section{Mathematical model of the synchronous generator}

The remaining part of the hydroplane to be modelled is the synchronous generator, where the electricity will be produced after transforming the mechanical energy to electrical energy. Many literatures addressed this topic [01, 02, 03, 04]. Hence we will limit ourselves in listing down the electrical dynamics equation of the synchronous generator:

$E_{0}=U+R l+j\left(\mathrm{X}_{\mathrm{s}}-X_{a}\right) \mathrm{l}=\mathrm{U}+\mathrm{R} 1+\mathrm{j} \mathrm{X}_{s} l$

Where: $U-$ is the voltage across the phase winding, $R$ - is the resistance of the winding phase, $L$ - load current, $X_{Q}$ - is leakage reactance, $E_{0}-$ is the induced electromotive force by the excitation flux, $X_{a}$ is dispersion reactance corresponding to reaction flux, and $X_{s}=X_{Q}+X_{a}$.

\section{SIMULATION RESULTS OF THE HYDROPOWER PLANT}

After acquisition of the mathematical models of the servomotor, turbine and synchronous generator, it is now possible to assemble the full model of the plant. We will be using implement PID controller to regulate the overall process. Figures 5 and 6 depict the simulation results. 


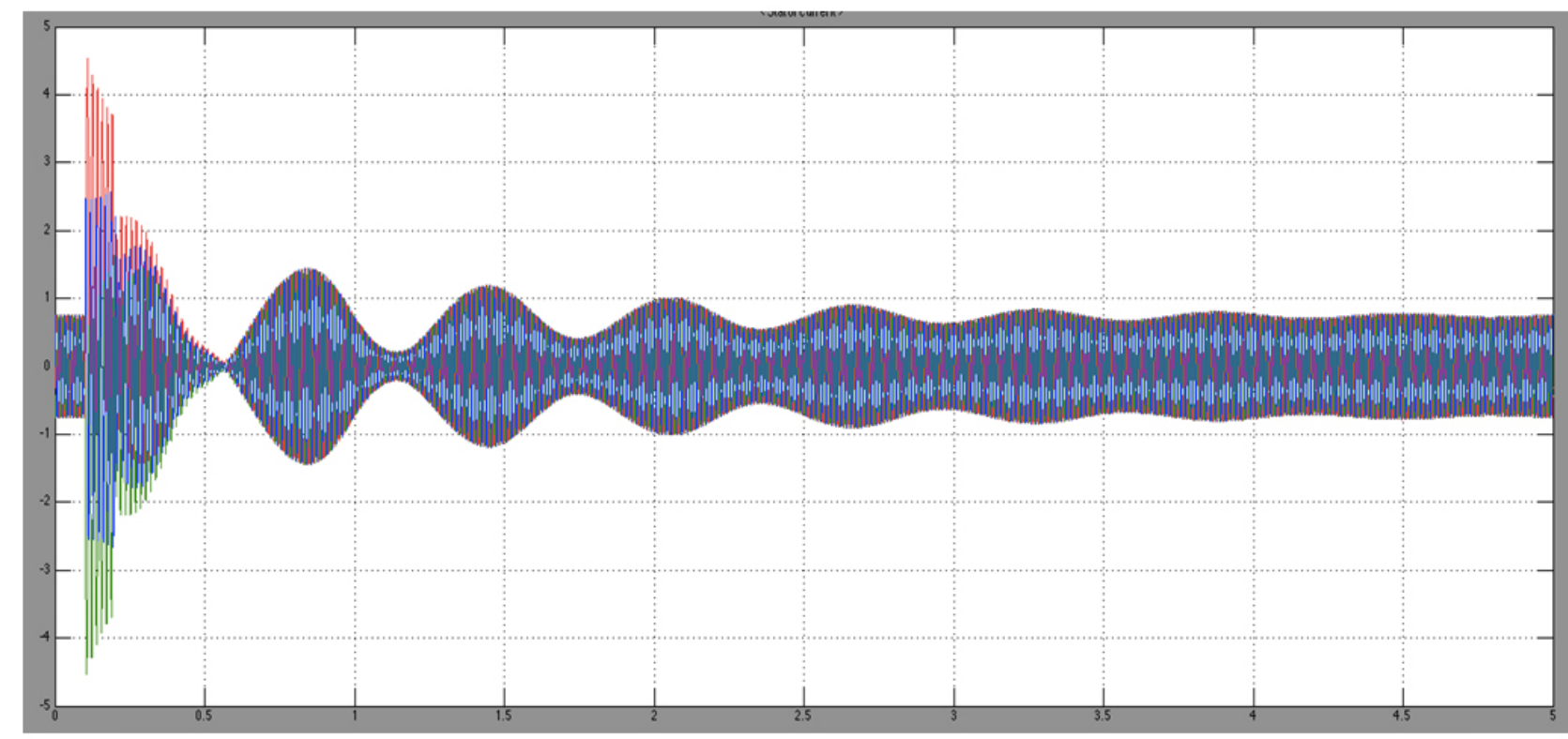

Figure 5: Stabilization process of the stator current of the synchronous generator $X$-axis: time; Y-axis Stator Current

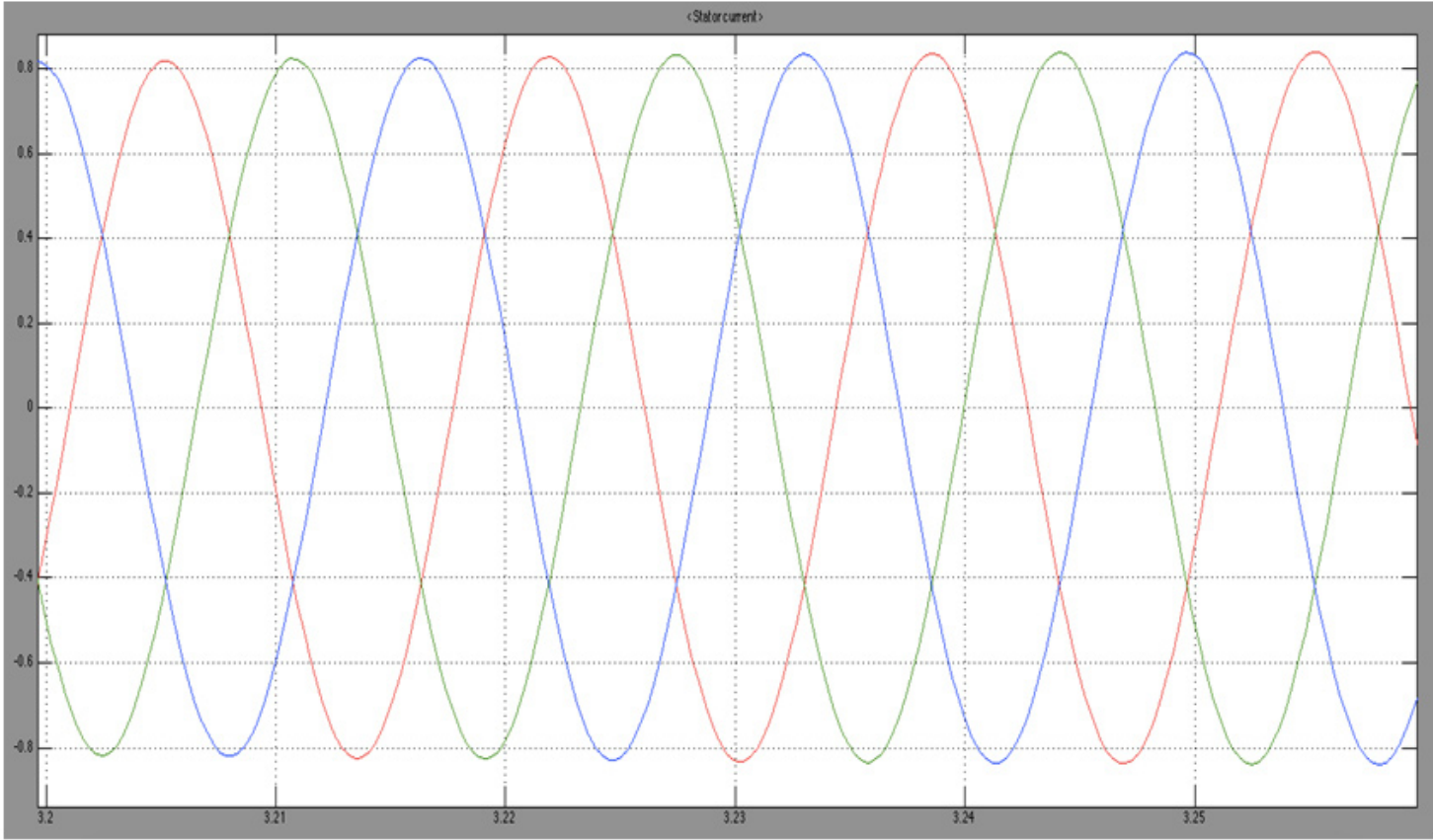

Figure 6: Steady-state stator current after 3 seconds

$X$-Axis: time; Y-Axis: Steady-state stator current

It is seen from Figure 5 that the control system requires 3 seconds in order to stabilize the outputs of different electromechanical systems: servomotor, gate and turbine. After regulating all the necessary parameters described in the sections above, the stator should show three-phase current, which should be fed to substation transformers for further distribution and usage.

Figure 6 confirms the statement given above. As it is clearly seen, when the load is changed, due to the presence of the transient and sub-transient reactance, envelop of three phase current shows under damped response at initial stage. After that, it gains the steady state characteristic.

The modelling and simulation of the hydropower plant is over. As it was highlighted earlier the control system managed to regulate different variables and therefore we assume that the first product (electricity) is released taking into consideration that linear model was used to describe the synchronous generator and many constraints on dynamics were adopted in the model of the hydro turbine. 


\section{FUTURE WORK}

This section discusses the first mechanical filtration of the water after being released from the hydropower plant, where the water pressure dropping with reference to its initial stage before passing within the blades. To tackle this issue, water flow has to be routed through pipeline system, the diameter of which is less than the turbine opening. This will cause additional pressure and increase the flow within the tubes. The rigidity factor of the pipelines will be analysed and its impact on the water flow continuity and pressure consistency.

\section{REFERENCES}

1) B. Bastian et al. Mathematical model of synchronous generator for diagnostics and settings tests of marine AVRS. Zeszyty problemowe Maszyny Elektryczne Nr 100/2013 Cz. II, 2013, pp. 181-184

2) S. E. Lyshevski: "Electromechanical Systems, Electric Machines and Applied Mechatronics", CRC Press, 2000

3) T. Eirola et al. Stability of mathematical model for systems of synchronous and asynchronous machines. Technische mechanic, 1996, pp. 237-244.

4) A. Barakat et al. Analysis of synchronous machine modeling for simulation and industrial applications. Simulation Modelling Practice and TheoryVolume 18, Issue 9, October 2010, Pages 1382-1396

5) G. Younkin et al. Electric servo motor equations and time constants. 7 pages.

Paper sent to revision: 26.07.2017.

Paper ready for publication: 18.08.2017. 